\title{
EFEKTIVITAS STRATEGI PEMASARAN SOSIAL INTERNAL DAN EKSTERNAL RENCANA PEMBANGUNAN PROGRAM PLPBK DI KELURAHAN SUNGAI LAIS KECAMATAN KALIDONI KOTAMADYA PALEMBANG
}

\author{
Oleh : \\ Ellys \& RY. Effendi \\ Fakultas Ekonomi Universitas IBA \\ Jalan Mayor Ruslan Palembang 30113
}

\begin{abstract}
Community-Based Settlement Neighborhood Setup (PLPBK) is a development program initiated and mobilized at village/rural level in village/regency areas. This program is a National Program, initiated by the Kementerian PUPR of through the Dirjen Cipta Karya to move the development in accordance with the needs and characteristics of the village / rural. Sungai Lais Village is one of 4 villages in Palembang that got this program. Activity begun in 2014 begins with social mapping to determine the most slums or priority areas, then will be built into a well-organized area of sanitation, drainage, clean water, open space and green open spaces and roads and bridges that are connected to every area in the village. Planning Expert Team to compile development plan with investment value \pm 7 billion, while direct aid fund (BLM PLPBK) equal to 1 billion. To cover the lack of investment, Marketing Experts and citizens engage in internal and external marketing strategy activities. Internal marketing strategy is a series of activities to provide understanding to the citizens about the importance of settlement arrangements well so that social and economic activities of society for the better. Citizen participation is not only energy and development ideas but also willingness to grant their land affected by the development plan. Internal marketing strategy is effective enough to influence the citizens, because there is willingness of citizens who grant the land even though not all of them. An external marketing strategy is an effort to influence stakeholders' willingness to intervene in development plans that have not been financed by BLM PLPBK funds. The result of City Government through Bappeda of Palembang City gives commitment to intervene development plan with funding scheme of RAPBD year 2018 until 2019.
\end{abstract}

Keywords: Effectiveness, Marketing, Social

\begin{abstract}
ABSTRAK
Penataan Lingkungan Permukiman Berbasis Komunitas (PLPBK) adalah program pembangunan yang dimulai dan digerakkan di tingkat kelurahan/desa diwilayah perkotaan/kabupaten. Program ini adalah Program Nasional, diprakarsai Kementerian
\end{abstract}


Pekerjaan Umum dan Perumahan Rakyat melalui Dirjen Cipta Karya untuk menggerakan pembangunan sesuai dengan kebutuhan dan karakteristik kelurahan/desa. Kelurahan Sungai Lais adalah salah satu dari 4 kelurahan di Kota Palembang yang mendapat program ini. Kegiatan dimulai 2014 diawali dari pemetaan sosial untuk menentukan kawasan yang paling kumuh atau kawasan prioritas, selanjutnya akan dibangun menjadi suatu kawasan yang tertata baik sanitasi, drainase, air bersih, ruang terbuka dan ruang terbuka hijau maupun jalan dan jembatan yang terkoneksitas kesetiap wilayah di kelurahan. Tim Ahli Perencanaan bersama warga menyusun rencana pembangunan dengan nilai investasi \pm 7 miliar, sedangkan dana bantuan langsung (BLM PLPBK) sebesar 1 miliar. Untuk menutupi kekurangan investasi, Tenaga Ahli Pemasaran dan warga melakukan kegiatan strategi pemasaran internal dan eksternal. Strategi pemasaran internal adalah serangkaian kegiatan untuk memberikan pemahaman kepada warga tentang pentingnya penataan lingkungan permukiman dengan baik agar kegiatan sosial dan ekonomi masyarakat menjadi lebih baik. Partisipasi warga tidak hanya tenaga dan ide-ide pembangunan tetapi juga kesediaan menghibahkan lahan mereka yang terdampak rencana pembangunan. Strategi pemasaran internal cukup efektif mempengaruhi warga, karena ada kesediaan warga yang menghibahkan lahannya walau belum semuanya. Strategi pemasaran eksternal adalah upaya untuk mempengaruhi stakeholder's agar bersedia mengintervensi rencana pembangunan yang belum terbiayai oleh dana BLM PLPBK. Hasilnya Pemerintah Kota melalui Bappeda Kota Palembang memberikan komitmen untuk mengintervensi rencana pembangunan dengan skema pendanaan RAPBD tahun 2018 sampai 2019.

\section{Kata kunci : Efektivitas, Pemasaran, Sosial}

\section{PENDAHULUAN}

\section{Latar Belakang}

Permasalahan kemiskinan di Indonesia sampai dengan saat ini masih menjadi pekerjaan besar bagi pemerintah, padahal hampir 70 tahun Indonesia merdeka. Sebagai pembagi besaran pendapatan perkapita, pertumbuhan penduduk yang tinggi adalah salah satu faktor yang signifikan berkontribusi menciptakan kemiskinan dan permasalahan sosial lainnya (Sadono Sukirno,2014:112).

Kemiskinan selalu identik dengan kekumuhan, pengangguran, tingkat kesehatan dan gizi yang rendah. Begitupun dengan pola pikir, sikap dan perilakunya lebih ditunjukkan kepada ketidakpedulian pada lingkungan dimana mereka hidup didalamnya. Program penataan lingkungan permukiman berbasis komunitas (PLPBK) 
P2KKP digulirkan untuk membangun sarana dan prasarana lingkungan yaitu sanitasi, drainase, air bersih, ruang terbuka dan ruang terbuka hijau, jalan dan jembatan yang terkoneksitas kesetiap wilayah di kelurahan. Diharapkan pembangunan ini dapat mengatasi permasalahan-permasalahan sosial, ekonomi dan lingkungan (SEL) masyarakat. Tenaga Ahli Perencanaan bersama warga melakukan Pemetaan Swadaya untuk menentukan wilayah terkumuh. Selanjutnya menyusun rencana pembangunan untuk kawasan terkumuh/prioritas dan kawasan-kawasan lain didalam wailayah Kelurahan Sungai Lais. Rencana pembangunan berjangka menengah dan panjang, dengan total investasi sebesar 7 miliar rupiah. Dana stimulan BLM PLPBK hanya 1 miliar rupiah, sehingga dibutuhkan intervensi dari Pemerintah Kota Palembang, BUMN/BUMD, swasta dan pihak-pihak peduli (stakeholder's) untuk merealisasi rencana pembangunan yang diusulkan masyarakat.

Tenaga Ahli Pemasaran bersama-sama warga yang dimotori Pokja Pemasaran, melakukan strategi pemasaran yaitu strategi pemasaran internal dan eksternal. Strategi pemasaran internal adalah upaya mempengaruhi pola pikir, sikap dan perilaku warga yang tidak peduli dan menganggap biasa saja kondisi lingkungan permukiman yang kumuh agar peduli dan cinta pada lingkungan tertata, bersih dan sehat, Visi mewujudkan "Lingkungan Permukiman Lestari, Aman dan Sehat Melalui Pengembangan Kapasitas Masyarakat Sungai Lais”, dapat terealisasi.

Serangkaian kegiatan strategi pemasaran internal adalah Diseminasi gagasan (Idea disemination), strategi Pengembangan merk (Development branding strategy) dan Pengembangan duta merk/pemasaran (Development branding/marketing ambasador). Strategi pemasaran eksternal adalah upaya untuk mempengaruhi stakeholder's agar bersedia mengintervensi rencana pembangunan yang belum terbiayai oleh dana BLM PLPBK. Kegiatan strategi pemasaran sosial eksternal dilaksanakan secara terus menerus dan berkesinambungan melalui beberapa kegiatan yaitu ; Identifikasi partner potensial (potential partner indentification), Presentasi (Presentation), Kegiatan Promosi (Promotion event), Kampanye media (campaign/media visit).

Pada bulan ke 4 ada penyerahan hibah lahan warga melalui Surat hibah tanah ke Pemerintah Kota untuk pembangunan MCK dan septictank komunal, bank sampah, IPAL 
dan balai pelatihan serta ruang terbuka. Pihak Pemkot sangat menanggapi hal ini dengan mendaftarkan surat hibah tanah tersebut pada Badan Pengelola Keuangan dan Asset Daerah (BPKAD). Pemerintah Kota Palembang melalui Kepala Bappeda memberikan Komitmen untuk mengintervensi rencana pembangunan penataan lingkungan kumuh dengan skema pendanaan APBD tahun 2018 dan 2019. Dari latar belakang ini, penulis sangat tertarik untuk meneliti fenomena yang terjadi setelah kegiatan strategi pemasaran rencana pembangunan program PLPBK dikelurahan Sungai Lais tahun 2016. Khususnya yang berkaitan dengan perilaku masyarakat di internal kelurahan dan tanggapan stakeholder's. Penelitian ini diberi judul 'Efektivitas Strategi Pemasaran Sosial Internal dan Eksternal Rencana Pembangunan Program PLPBK di Kelurahan Sungai Lais Kecamatan Kalidoni Kotamadya Palembang."

\section{Perumusan Masalah}

Dari latar belakang tersebut, maka penulis merumuskan permasalahan pada penelitian ini yaitu ;

Bagaimana efektifitas strategi pemasaran sosial internal dan eksternal rencana pembangunan Program PLPBK Kelurahan Sungai Lais Kecamatan Kalidoni melalui analisis SWOT.

\section{Tujuan Penelitian}

Untuk mengetahui bagaimana efektifitas strategi pemasaran sosial internal dan eksternal rencana pembangunan Program PLPBK Kelurahan Sungai Lais melalui analisis SWOT.

\section{Kontribusi Penelitian}

Secara praktis, hasil penelitian ini diharapkan dapat menjadi;

1. Pembelajaran dan masukan bagi masyarakat Kelurahan Sungai Lais khususnya Lembaga Keswadayaan Masyarakat (LKM) Anugrah Bersama agar mereka dapat terus melanjutkan kegiatan strategi pemasaran sosial internal sehingga secara perlahan akan terlihat perubahan-perubahan yang signifikan terhadap pola pikir, sikap dan perilaku untuk mewujudkan visi pembangunan menuju "Lingkungan Permukiman Lestari, Aman dan Sehat Melalui Pengembangan Kapasitas Masyarakat Sungai Lais”. 
2. Pembelajaran dan masukan bagi masyarakat Kelurahan Sungai Lais khususnya Lembaga Keswadayaan Masyarakat (LKM) Anugrah Bersama agar mereka dapat terus melanjutkan kegiatan strategi pemasaran sosial eksternal untuk mempengaruhi para pengambil kebijakan hingga dapat mewujudkan "Lingkungan Permukiman Lestari, Aman dan Sehat Melalui Pengembangan Kapasitas Masyarakat Sungai Lais".

3. Bahan pertimbangan untuk pengambilan keputusan pemasaran bagi programprogram pembangunan Pemerintah selanjutnya.

4. Suatu karya tulis dosen sebagai pemenuhan kewajiban Tri Dharma Perguruan Tinggi penulis.

Secara Teoritis, hasil penelitian diharapkan dapat menjadi;

1. Bahan referensi bagi peneliti-peneliti selanjutnya.

2. Hasil penelitian ini untuk menambah hasanah penelitian baik didalam jurnal Jemasi, repositori dan perpustakaan.

3. Menjadi penelitian awal bagi penulis untuk penelitian selanjutnya.

4. Pengetahuan dan kompetensi penulis sebagai seorang dosen.

\section{STUDI PUSTAKA}

Pemasaran

American Marketing Asociation (AMA), mendifisikan pemasaran adalah suatu fungsi organisasi dan serangkaian proces untuk menciptakan, mengomunikasikan, dan memberikan nilai pada pelanggan dan untuk mengelola hubungan pelanggan dengan cara yang menguntungkan organisasi dan pemangku kepentingannya. (dalam Buchori Alma, 2014:151). Selanjutnya dijelaskan bahwa pemasaran sebagai suatu proses perencanaan, dan pelaksanaan perencanaan penetapan harga, promosi, distribusi dari ide-ide, barangbarang dan jasa-jasa untuk menciptakan pertukaran yang memuaskan tujuan-tujuan individal dan organisasi. Kemudian Philip Kotler, (2010:8) mendifinisikan bahwa pemasaran sebagai proses sosial dan manajerial yang dilakukan seseorang atau kelompok untuk memperoleh apa yang mereka butuhkan dan inginkan melalui penciptaan, penawaran dan pertukaran produk-produk yang bernilai dengan yang lainnya. Manullang, (2012:193) menguraikan bahwa pemasaran atau marketing merupakan suatu proses dinamis dari dunia usaha, terdiri dari jumlah aktifitas yang berkesinambungan yang merupakan interaksi dari sejumlah kegiatan yang dimulai dari mengajukan ide-ide tentang produk yang di hasilkan, selanjutnya diusahakan hal tersebut menjadi kenyataan 
berupa barang atau jasa untuk kemudian disampaikan ketangan konsumen untuk memuaskan kebutuhannya.

\section{Pemasaran sosial}

Pemasaran sosial adalah seluruh rangkaian kegiatan mensosialisasikan, mengkomunikasikan ide-ide gagasan sosial untuk perubahan pola pikir, sikap dan perilaku masyarakat (Juknis Pemasaran PLP-BK PNPM Mandiri Perkotaan, 2009:5). Selanjutnya dikatakan Pemasaran sosial dilakukan untuk mengkampanyekan programprogram Pemerintah dalam upaya melakukan perubahan sosial didalam kehidupan masyarakat.

\section{Efektivitas}

Hal yang penting bagi seorang pemasar adalah bagaimana proses sosial dan managerial didalam kegiatan pemasaran dapat mencapai tujuan pemasaran secara efektif dan efisien. Kegiatan pemasaran yang efektif adalah kegiatan pemasaran yang membawa hasil (KBBI, 2015 : 22), Sedangkan efektifitas adalah kemampuan untuk memperoleh hasil sesuai dengan tujuan yang telah ditetapkan. (Ernie Tisnawati Sule, 2014: 7). Hasil yang ingin dicapai dalam kegiatan strategi pemasaran internal pada rencana pembangunan penataan lingkungan permukiman berbasis komunitas (PLPBK) adalah respon warga pada program tersebut dan secara perlahan dapat merubah pola pikir, sikap serta perilaku masyarakat untuk hidup sehat didalam lingkungan permukiman yang tertata, bersih, aman dan lestari sesuai dengan Visi Masyarakat Kelurahan Sungai Lais yaitu mewujudkan"Lingkungan Permukiman Lestari, Aman dan Sehat Melalui Pengembangan Kapasitas Masyarakat Sungai Lais". Respon ini dapat diwujudkan dalam bentuk kesediaan masyarakat untuk memelihara lingkungan permukiman dengan baik seperti pengelolaan sampah, limbah rumah tangga, dan saluran air. Respon masyarakat juga ditunjukkan dari sikap dan perilaku warga untuk menghibahkan lahan mereka yang terdampak rencana pembangunan program PLPBK sekaligus bersedia untuk memelihara dan mengelola sarana dan jalan, jembatan, drainase, MCK dan septictank (sanitasi), Instalasi Pengelolaan Air Limbah (IPAL), pengolahan dan bank sampah, ruang terbuka hijau, serta balai pelatihan untuk pengembangan UKM. Sedangkan hasil yang ingin dicapai pada kegiatan pemasaran eksternal adalah adanya 
respon dari pihak-pihak yang berkepentingan (stakeholder's) agar bersedia mengintervensi rencana pembangunan yang telah ditetapkan didalam Rencana Tindak Penataan Lingkungan Permukiman (RTPLP 2015:47) Kelurahan Sungai Lais. Respon tersebut diwujudkan dalam bentuk dimasukkannya rencana pembangunan kedalam RAPBD tahun berikutnya.

\section{Strategi Pemasaran Sosial Internal dan Eksternal}

Strategi pemasaran sosial program PLPBK adalah seluruh rangkaian kegiatan sosialisasi, komunikasi dan promosi gagasan-gagasan sosial dan hasil perencanaan partisipatif yang dituangkan dalam RTPLP kepada masyarakat, dunia usaha, LSM, Perguruan Tinggi, Pemerintah kota, Pemerintah provinsi, Pemerintah pusat dan kelompok peduli lainnya. (Juknis Pemasaran PLP-BK PNPM Mandiri Perkotaan, 2009:5). Sedangkan menurut Buchori Alma (2014:52) strategi pemasaran adalah serangkaian tindakan terpadu untuk menuju keunggulan kompetitif yang berkelanjutan, bila dirangkai kalimat strategi pemasaran menjadi strategi pemasaran sosial, maka pengetiannya dapat dimodifikasi menjadi serangkaian tindakan terpadu untuk menuju keunggulan kompetitif yang berkelanjutan didalam kehidupan sosial ekonomi dan lingkungan masyarakat. Strategi pemasaran sosial program PLPBK terdiri dari 2 kelompok strategi yaitu strategi pemasaran sosial internal dan eksternal.

\section{Strategi Pemasaran Sosial Internal}

\section{Diseminasi gagasan (Idea Disemination)}

Yaitu suatu kegiatan yang ditujukan kepada suatu kelompok target atau individu agar mereka memperoleh informasi, timbul kesadaran, menerima dan akhirnya memanfaatkan informasi tersebut.(http//skdibatola/5/12/2016). Deseminasi gagasan dilakukan melalui kegiatan forum diskusi warga/ group discussion forum (FGD) yang dimotori Lembaga Keswadayaan Masyarakat Anugrah Bersama, dilaksanakan dengan mengundang seluruh ketua RW dan RT ditambah dengan 5 orang perwakilan masyarakat untuk setiap RT. Seluruh yang hadir berpartisipasi untuk mengemukakan permasalahanpermasalahan yang ada dalam lingkungan permukiman mereka. Masyarakat diberikan penjelasan tentang maksud dan tujuan program PLPBK dan diminta mengisi kuisioner 
yang mempertanyakan kondisi nyata tentang sanitasi, jalan lingkungan, air bersih, drainase dan pengelolaan sampah. Dari jawaban masyarakat tersebut dapat diketahui potensi dan permasalahan yang ada didalam lingkungan permukiman mereka. Masyarakat melakukan evaluasi diri dan menyadari serta mengerti tentang pentingnya penataan lingkungan permukiman yang baik. Melalui forum ini juga masyarakat diberikan kesempatan untuk mengemukakan ide-ide pembangunan untuk penataan lingkungan mereka agar menjadi Lingkungan Permukiman Lestari, Aman dan Sehat Melalui Pengembangan Kapasitas Masyarakat Sungai Lais” .(RTPLP Kelurahan Sungai Lais,2015: 41).

\section{Strategi Pengembangan Merk (Development branding strategy)}

Merk adalah nama, istilah, simbol atau rancangan atau kombinasi lain (Kotler, 2010:112). Selanjutnya dijelaskan, merk ditujukan untuk membangun nilai, kesadaran dan citra dari suatu barang dan jasa. Merk pemasaran sosial rencana pembangunan progam PLPBK di Kelurahan Sungai Lais. Merk Ikan Lais dipilih warga karena didaerah aliran sungai Musi dan anak sungainya banyak hidup ikan Lais sebagai salah satu ikan asli daerah Sumatera Selatan.

\section{Mengembangkan duta merk/pemasaran (Development branding/marketing ambasador).}

Duta merk atau duta pemasaran adalah seseorang atau kelompok yang dipekerjakan dengan kontrak oleh sebuah organisasi untuk mempromosikan suatu merk produk atau jasa (Wikipedia, 27/12/2016). Mengembangkan duta merk atau duta pemasaran adalah dengan memilih seseorang atau kelompok yang disepakati dengan musyawarah menjadi duta merk atau duta pemasaran. Kelompok ini disebut Pokja Pemasaran dan diketuai oleh seorang ketua sebagai juru bicara didalam mengkomunikasikan dan mempromosikan rencana pembangunan program PLPBK. yang masih membutuhkan pembiayaan. 


\section{Strategi Pemasaran Sosial Eksternal}

\section{Identifikasi partner potensial (potential partner indentification).}

Identifikasi partner potensial (potential partner indentification) adalah kegiatan menentukan calon-calon partner potensial atau calon stakeholder's yang dianggap berpotensi dan berkompeten untuk melakukan intervensi rencana pembangunan program PLPBK yang telah dituangkan didalam rencana tindak penataan lingkungan permukiman (RTPLP). Partner tersebut diantaranya Pemerintah Kota Palembang. (Dok.Strategi Pemasaran Kel.Sungai Lais, 2016:42).

\section{Presentasi (Presentation)}

Dalam Kamus Besar Bahasa Indonesia (KBBI, 2015 : 102), presentasi adalah mempertunjukkan, memaparkan dan mendiskusikan kepada pihak-pihak tertentu yang terkait. Dalam kaitannya dengan pemasaran sosial eksternal, pokja pemasaran melakukan kegiatan presentasi kepada calon stakeholder's yang akan mengintervensi rencana pembangunan program PLPBK yaitu Pemerintah Kota Palembang, Badan Perencanaan Pembangunan Kota Palembang (Bappeda), Dinas PU dan Tata Kota serta lembagalembaga lain.

\section{Kegiatan promosi (Event Promotion)}

Kegiatan promosi berfungsi sebagai alat komunikasi antara perusahaan (pihak yang menawarkan) dengan konsumen (pihak yang akan melakukan pembelian). Selanjutnya promosi juga berfungsi untuk mempengaruhi calon pembeli agar bersedia melakukan pembelian (Rambat, 2014:178). Pokja pemasaran mengkomunikasikan dan mempengaruhi calon stakeholder's internal dan eksternal dengan kegiatan jalan santai, pemasangan spanduk didepan kantor Lurah Sungai Lais, pemasangan banner dan pembagian leafled di pameran Palembang Expo serta diacara senam pagi Kambang Iwak, pemasangan papan nama didepan posko LKM Anugrah Bersama, penayangan video 3D kawasan prioritas pembangunan saat presentase dan website www.anugrahbersama.org yang memuat berita-berita kegiatan pembangunan dan pemasaran pokja. 


\section{Kampanye media (campaign/media visit).}

Kampanye media (campaign/media visit) ditujukan untuk mengkomunikasikan dan mempengaruhi stakeholder's melalui media cetak, elektronik dan website ; www.anugrahbersama.org

\section{Program Penataan Lingkungan Permukiman Berbasis Komunitas (PLPBK)}

Program penataan lingkungan permukiman berbasis komunitas (PLPBK) adalah Program Penataan Lingkungan Permukiman Berbasis Komunitas (Neighbourhood Development) yaitu program penataan kawasan permukiman untuk memenuhi standart kebutuhan hidup layak melalui pemenuhan kebutuhan air bersih, sanitasi, drainase, penerangan, pengamanan dari bencana kebakaran/banjir, ruang terbuka hijau dan ruang sosialisasi masyarakat sehingga dapat mendukung pertumbuhan ekonomi warga. (Petunjuk Umum PLPBK PNPM Mandiri Perkotaan, 2014 :3). Pendanaan untuk menjalankan program ini adalah Pemerintah pusat melalui Kementerian PUPERA berupa dana stimulan BLM PLPBK, selanjutnya pendanaan untuk rencana pembangunan berikutnya dilanjutkan oleh masyarakat melalui LKM berupaya membangun kerjasama dan kemitraan dengan Pemerintah Daerah, BUMN/BUMD, perusahaan swasta dan pihak-pihak peduli, berharap untuk mengintervensinya.

\section{METODE PENELITIAN}

\section{Lokasi dan Waktu Penelitian}

Lokasi penelitian ini di Kelurahan Sungai Lais Kecamatan Kalidoni kota Palembang provinsi Sumatera Selatan dan waktu penelitian April-Juni 2017.

\section{Variabel Penelitian.}

Variabel-variabel yang akan diteliti dalam penelitian ini adalah variabel efektivitas, strategi pemasaran sosial internal dan eksternal. Variabel-variabel ini akan dianalisis secara deskriptif dengan menguraikannya kedalam bentuk Dimensi variabel dan indikator impiris sehingga penulis dapat menginterpretasikannya secara kualitatif dan menganalisisnya dengan analisis SWOT. 
Tabel 1. Variabel Efektivitas Strategi Pemasaran Sosial Internal

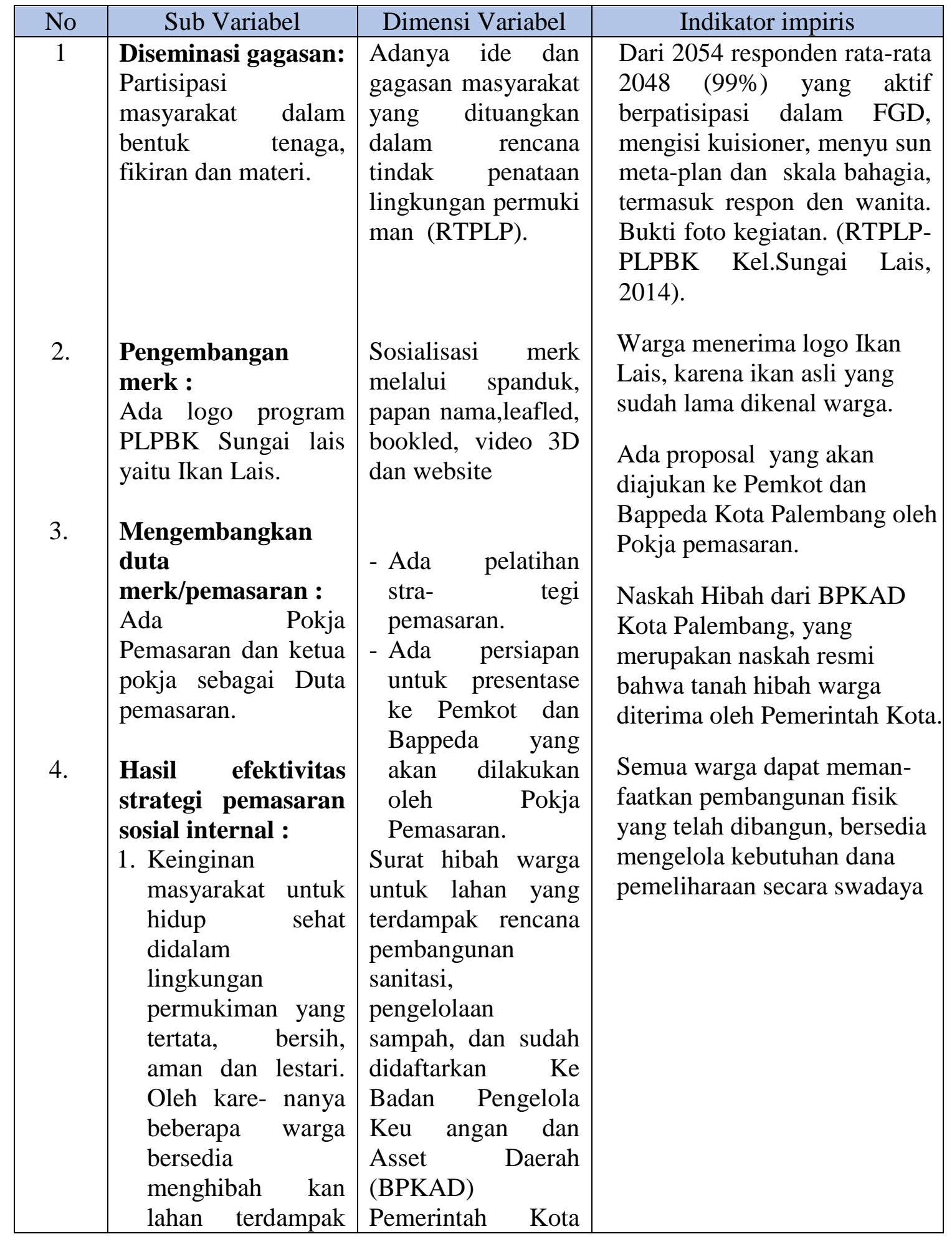




\begin{tabular}{|c|c|}
\hline $\begin{array}{l}\text { rencana pembangu } \\
\text { nan kepada } \\
\text { Pemkot. } \\
\text { 2. Kesediaan warga } \\
\text { untuk mengelola } \\
\text { dan memelihara } \\
\text { pemba ngunan } \\
\text { fisik yang telah } \\
\text { dibangun }\end{array}$ & $\begin{array}{l}\text { Pemilik lahan hibah } \\
\text { dan warga bersedia } \\
\text { menge lola dan } \\
\text { memelihara } \\
\text { pembangunan fisik } \\
\begin{array}{l}\text { yang telah } \\
\text { dibangun. }\end{array}\end{array}$ \\
\hline
\end{tabular}

Sumber : Hasil survey

Tabel 2. Variabel Efektivitas Strategi Pemasaran Sosial Eksternal

\begin{tabular}{|c|c|c|c|}
\hline No & Sub Variabel & Dimensi Variabel & Indikator impiris \\
\hline 1. & $\begin{array}{l}\text { Presentasi : } \\
\text { a. Adanya kesepakatan } \\
\text { waktu dan tempat } \\
\text { presentasi } \\
\text { b. Ada materi } \\
\text { presentasi } \\
\text { c. Ada rencana } \\
\text { pemba -ngunan } \\
\text { yang akan } \\
\text { ditawarkan untuk } \\
\text { diintervensi } \\
\text { Pemerintah Kota }\end{array}$ & $\begin{array}{l}\text { Diterima proposal } \\
\text { Penawaran Rencana } \\
\text { Pembangunan } \\
\text { program PLPBK } \\
\text { oleh Pemkot melalui } \\
\text { Bappeda untuk } \\
\text { mengintervensi } \\
\text { rencana } \\
\text { pembangunan fisik }\end{array}$ & $\begin{array}{l}\text { Komitmen Pemerintah Kota } \\
\text { dalam hal ini Bappeda sebagai } \\
\text { lembaga pembuat perencanaan } \\
\text { pembangunan di Kota } \\
\text { Palembang, dalam bentuk Surat } \\
\text { Komitmen yang ditandatngani } \\
\text { Kepala Bappeda Kota } \\
\text { Palembang. }\end{array}$ \\
\hline 2. & $\begin{array}{l}\text { Kegiatan promosi : } \\
\text { a. Kegiatan } \\
\text { sosialisasi program } \\
\text { PLPBK dengan } \\
\text { meng hadirkan } \\
\text { stakeholder's } \\
\text { b. Mengikuti } \\
\text { pameran } \\
\text { Palembang Expo. } \\
\text { c. Pembagian leafled, } \\
\text { dan bookled } \\
\text { kepada } \\
\text { stakeholder's, pena } \\
\text { yangan video 3D }\end{array}$ & $\begin{array}{l}\text { a. Ada komunikasi } \\
\text { untuk mempengaruhi } \\
\text { stakeholder's } \\
b \text {. Ada tools } \\
\text { pemasaran }\end{array}$ & $\begin{array}{l}\text { Kehadiran stakeholder's } \\
\text { diantaranya; Walikota Kota } \\
\text { Palembang dengan jajarannya, } \\
\text { Bappeda,Satker PUCK dan } \\
\text { Tokoh-tokoh masyarakat. }\end{array}$ \\
\hline
\end{tabular}




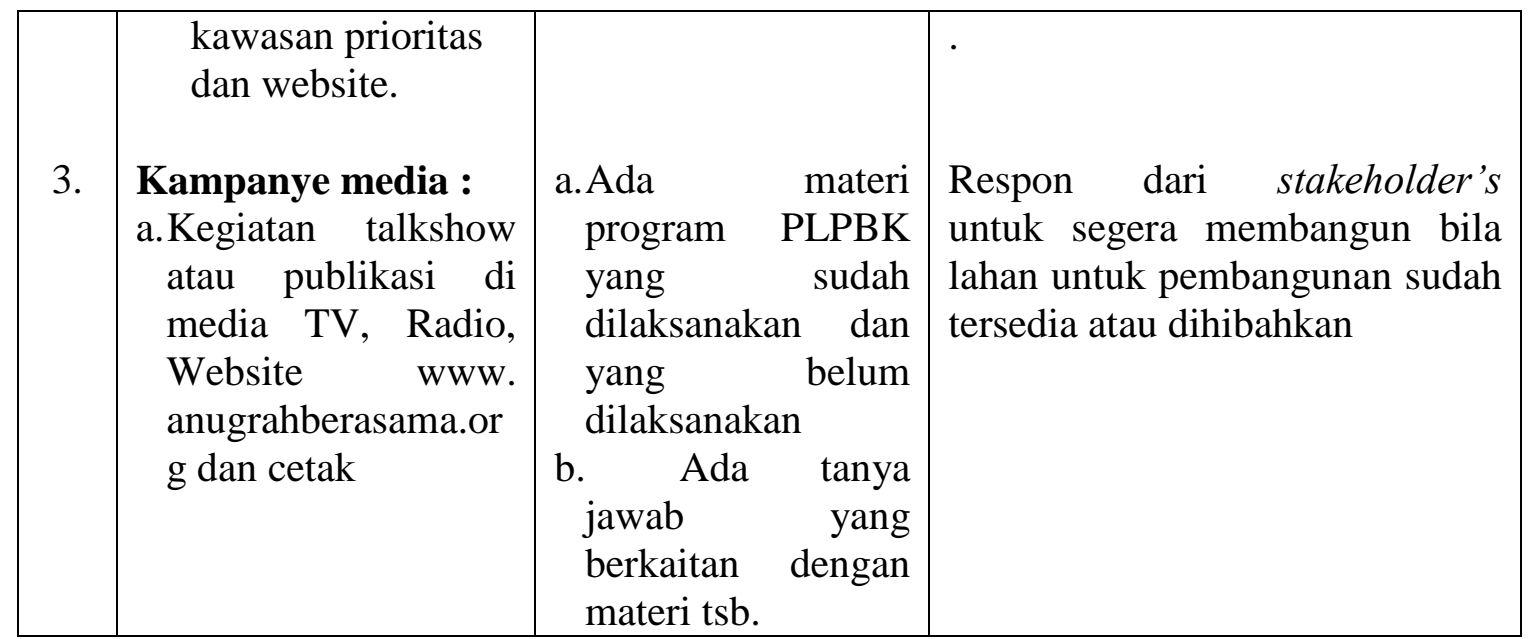

Sumber : Hasil survey

\section{Model Yang Digunakan}

Model yang digunakan untuk menganalis penelitian ini adalah analisis SWOT. Melalui unsur-unsur kekuatan, kelemahan dari tiap-tiap sub-sub variabel strategi pemasaran sosial akan dipadukan untuk memanfaatkan peluang dan tantangan.

\section{Rancangan Penelitian.}

Penelitian ini dirancang dengan menggunakan desain penelitian deskriptif kualitatif yaitu menguraikan variabel-variabel yang akan diteliti dengan data-data yang mendukung kemudian ditelaah dengan teori-teori yang relevan.(Sugiono, 2003: 45).

\section{Tehnik Pengumpulan Data.}

Jenis data yang mendukung variabel-variabel strategi pemasaran sosial internal dan eksternal dibagi menjadi 2 kelompok data yaitu data primer dan sekunder. Data primer merupakan data informasi dari responden / masyarakat yang diwakili oleh LKM, diperoleh melalui wawancara dan survey lapangan. Data sekunder adalah data hasil olahan yang sudah berbentuk dokumen. Data-data tersebut tertuang dalam dokumen RTPLP Kelurahan Sungai Lais, 2015 dan dokumen Strategi Pemasaran Kelurahan Sungai Lais, 2016.

\section{Analisis Data.}

Data-data atau informasi-informasi yang telah terkumpul, akan dianalisis dengan analisis SWOT kemudian di kroscek dengan hasil yang telah dicapai sampai dengan sekarang. 


\section{Tolok Ukur Efektivitas Dalam Kegiatan Strategi Pemasaran Sosial}

Yaitu tercapainya sasaran pemasaran :

a. Partisipasi masyarakat dalam bentuk tenaga, fikiran dan materi. Bukti berupa fotofoto kegiatan.

b. Hibah lahan warga yang terdampak rencana pembangunan program PLPBK. kepada Pemerintah Kota Palembang. Bukti berupa naskah hibah BPKAD.

c. Komitmen Pemerintah Kota Palembang melalui Kepala Bappeda dan stakeholder's lain. Bukti berupa surat komitmen.

Deskripsi SWOT : "Efektivitas Strategi Pemasaran Sosial Internal Rencana Pembangunan Program PLPBK di Kelurahan Sungai Lais Kecamatan Kalidoni Kotamadya Palembang."

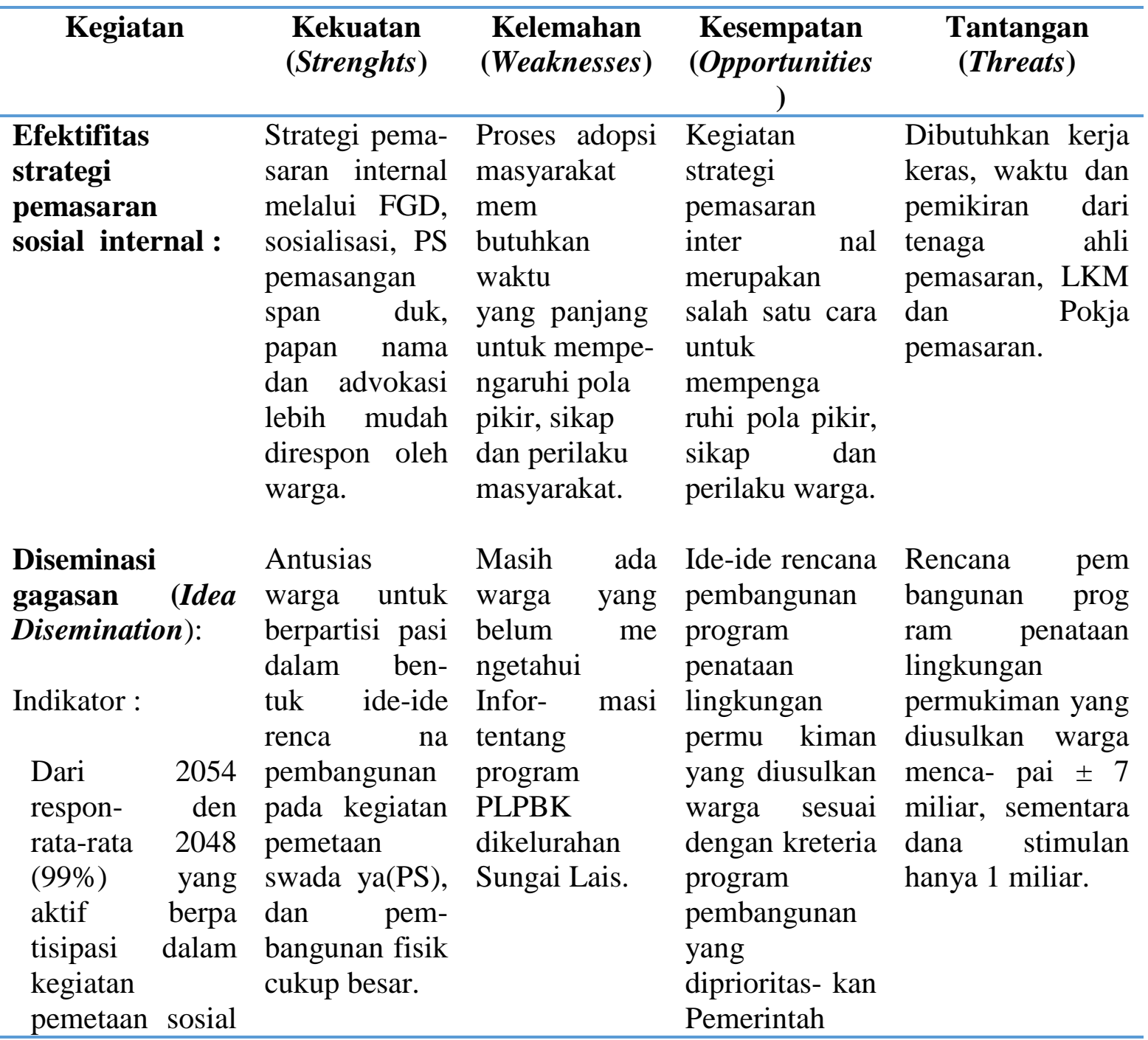




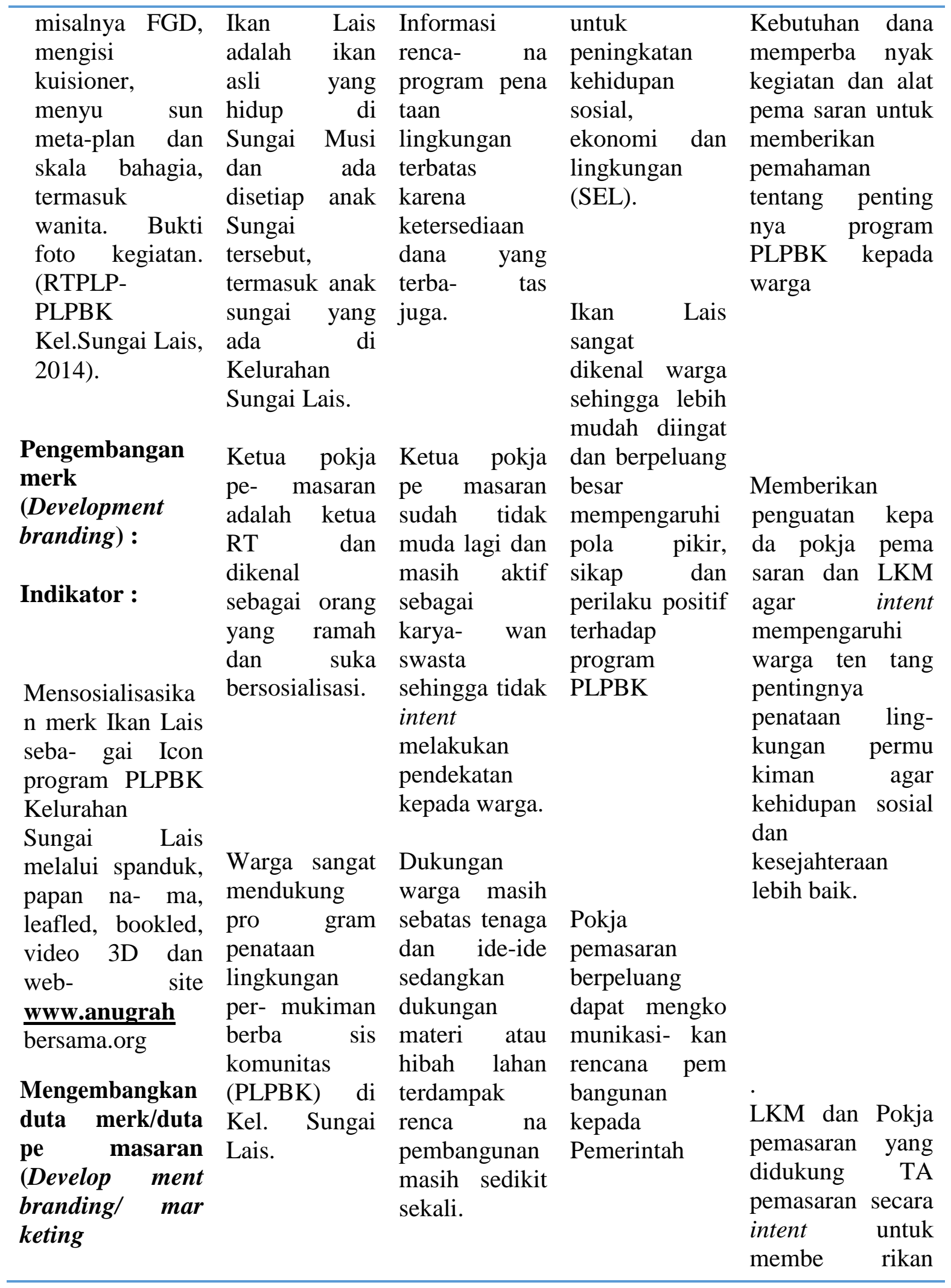




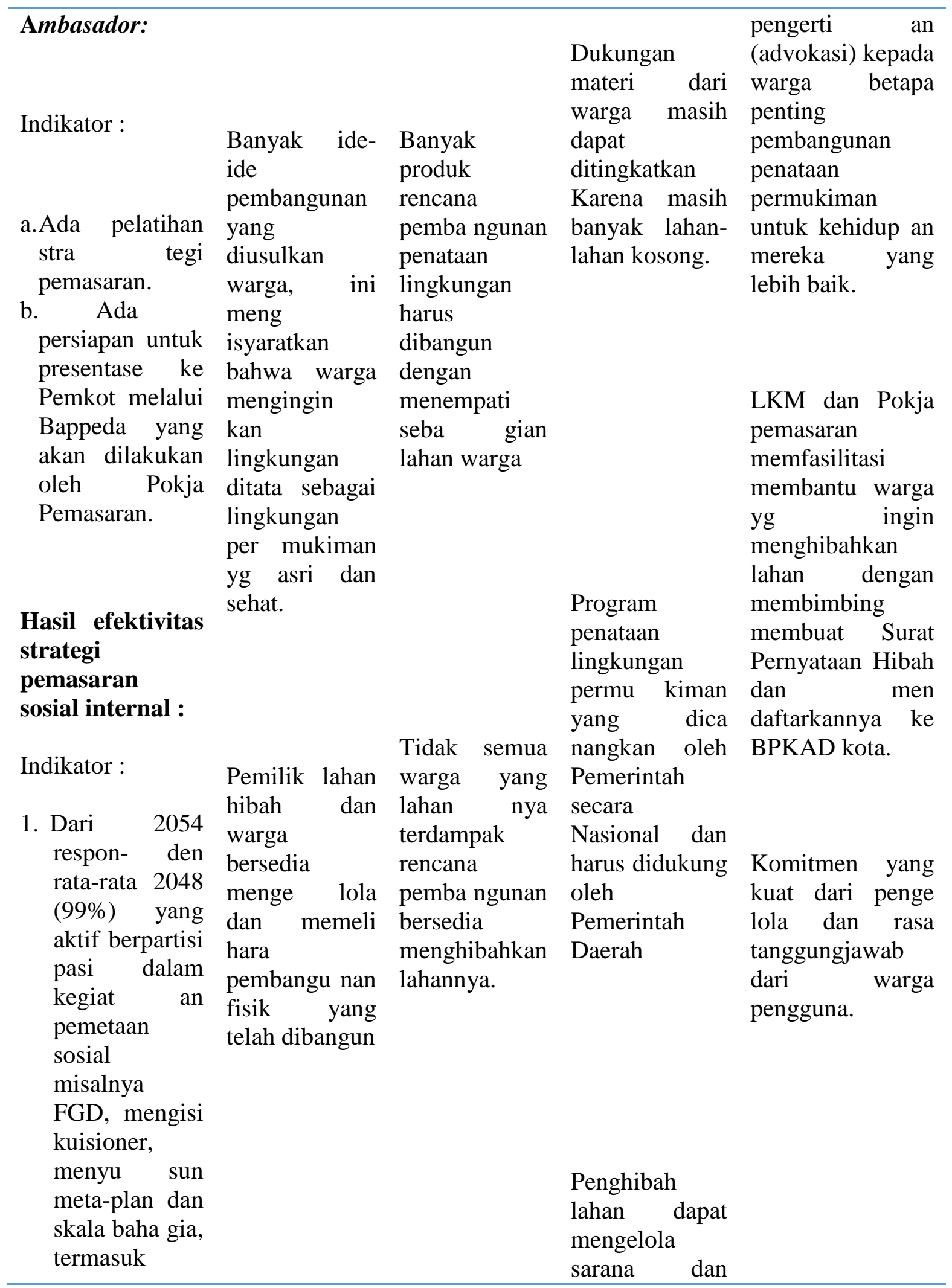




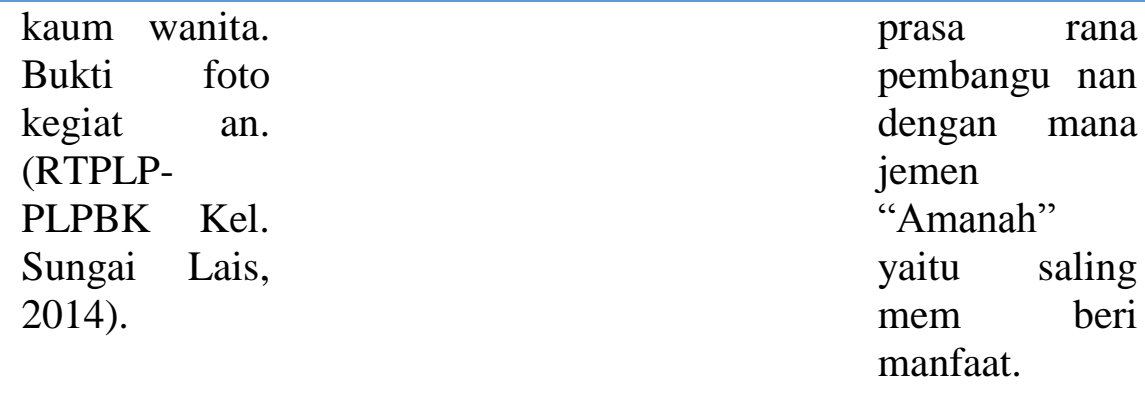

2. Keinginan

masya rakat

untuk hidup

sehat didalam

ling kungan

permuki man

yang tertata,

bersih, aman

dan lestari.

Oleh kare-

nanya

beberapa

warga telah

menghibahkan

lahan

terdampak

rencana

pemba- ngunan

kepada

Pemkot.

(Naskah Hibah

BPKAD)

3. Kesediaan

warga untuk

mengelola dan

memelihara

pembangunan

fisik yang telah

dibangun

(Lisan)

Sumber : Dokumen RTPLP dan survey, 2016

Aggresive Strategy (S-O), Turn Around Strategy (S-T) dan Capaian Hasil

\begin{tabular}{|c|c|c|}
\hline & Kesempatan /Opportunities & \multicolumn{2}{|c|}{ Tantangan/Threats } \\
\hline & 1. Strategi pemasaran internal salah satu & 1. Dibutuhkan kerja keras, TA \\
\hline
\end{tabular}




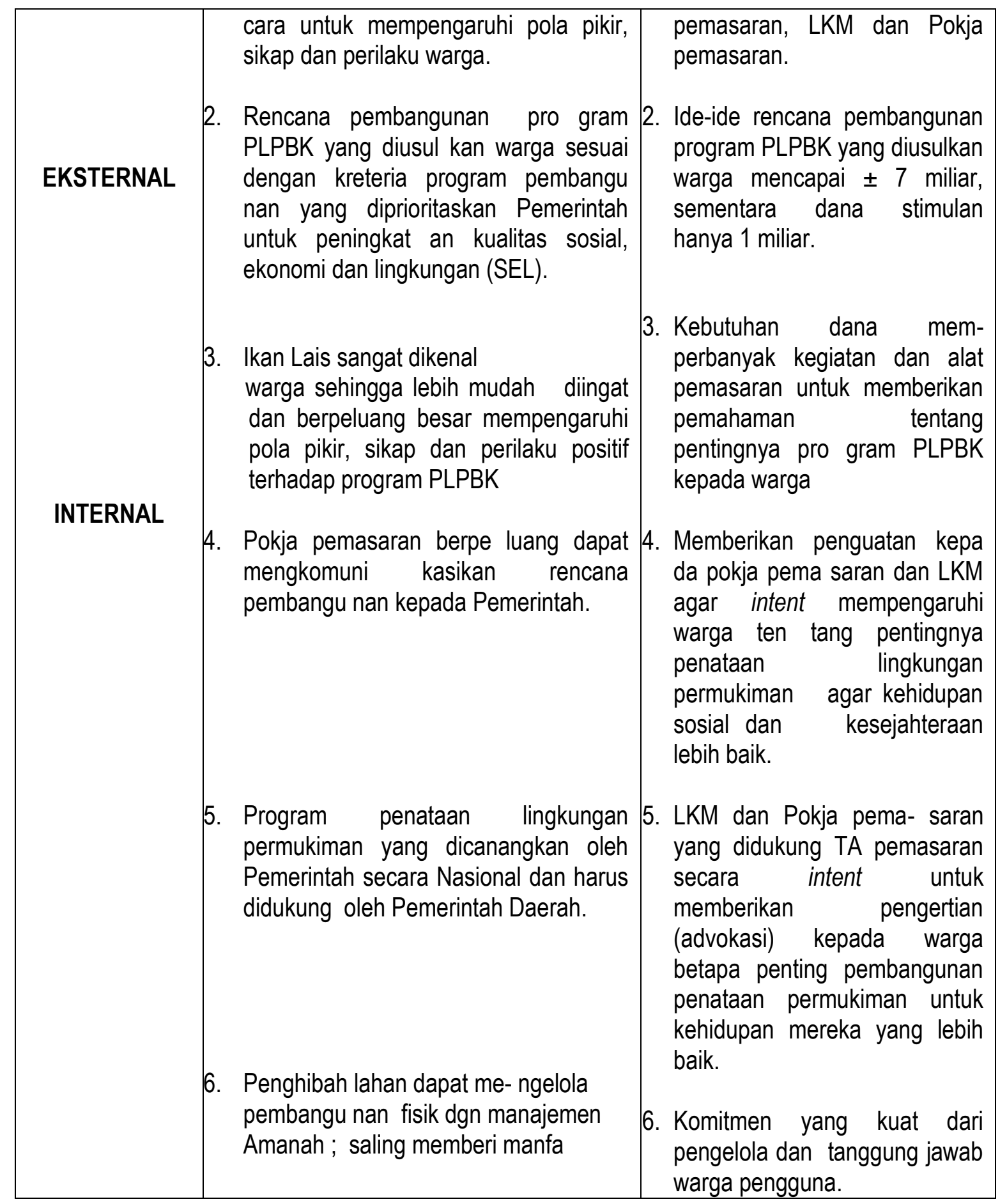


Turn Around Strategy

(S-T)
1. Strategi pemasaran inter nal melalui FGD, sosiali sasi, Pemetan swadaya, pe masangan spanduk, papan nama dan advokasi lebih mudah direspon warga.

2. Antusias warga untuk berpartisi pasi dalam ben- tuk ide-ide rencana pembangunan pemetaan swada ya(PS), dan pembangunan fisik

3. Ikan Lais adalah ikan asli yang hidup di Sungai Musi dan ada disetiap anak Sungai tersebut, termasuk anak sungai yang ada di Kelurahan Sungai Lais.

4. Ketua pokja pemasaran adalah ketua RT dan dikenal sebagai orang yang ramah dan suka bersosialisasi.

5. Banyak ide-ide pembngunan yang diusulkan warga, ini meng isyaratkan bahwa warga mengingin kan lingkungan ditata sebagai lingkungan permu kiman yg asri dan sehat.
1. Mengkomunikasikan prog ram PLPBK dengan icon ikan Lais pada berbagai kegiatan sosial budaya warga. Misal nya memberikan advokasi dikegiatan majelis Taklim dan mendatangi warga terdam pak door to door dipelopori oleh Ketua RT dan RW.

2. Komunikasi intent dan memberikan ekspektasi atau harap an kepada Peng urus LKM dan pokja pemasaran serta warga yang menghibahkan lahan nya dapat memanfaat kan produk pembangunan fisik PLPBK untuk kebutuhan sendiri dan warga lain dengan perjanjian biaya pemeliharaan ditanggung bersama. Misalnya pemba ngunan MCK, diupayakan dibangun 2 pintu, dimana 1 pintu untuk pengelola dan 1 pintu lagi untuk warga lain namun mereka dibebani sejumlah biaya untuk pemeliharaan dan air bersih. Warga yang menghibahkan lahan untuk pembangunan IPAL dibawah tanah, diatasnya dapat dijadikan ruang terbu ka untuk warga dan anak-anak bersosialisasi. Atau dapat dibangun tempat pengelolaan/bank sampah. Begitu pula lahan hibah untuk pembangunan Balai Pelatihan, penghibah dapat mengelo-
1. Memotivsi warga bahwa bila ada ruang terbuka diatas lahan IPAL maka digunakan untuk kegiatan sosial warga seperti lomba peringatan Hari Kemerdekaan RI, senam pagi atau lapangan olahraga, sehingga warga betul-betul merasakan manfaatnya daripada dibiarkan saja sebagai lahan-lahan kosong bersemak belukar.

2. Memotivsi warga bahwa bila ada Balai Pelatihan KSM maka dapat digunakan untuk berbagai kegiatan untuk mening katkan kompetensi warga sehingga mampu mandiri secara sosial dan ekonomi. Balai Pelatihan juga dapat disewakan dengan harga yang ringan untuk kegiatan pernikahan atau sunatan. 


\begin{tabular}{|ll|}
\hline & $\begin{array}{l}\text { lanya dengan pola manaje- } \\
\text { men "Amanah" dimana pene }\end{array}$ \\
$\begin{array}{ll}\text { 6. Pemilik lahan hibah dan } \\
\text { warga bersedia menge } \\
\begin{array}{l}\text { lola dan memelihara } \\
\text { pembangunan fisik yang } \\
\text { telah dibangun. }\end{array}\end{array}$ & $\begin{array}{l}\text { rimarela mengeluarkan sejum } \\
\text { lah dana untuk pemeliharaan. }\end{array}$ \\
\hline
\end{tabular}

\section{Capaian Hasil Strategi Pemasaran Internal :}

1. Rencana pembangunan PLPBK dikawasan prioritas telah terlaksana dengan bantuan tenaga, pemikiran dan materi warga secara sukarela.

2. Ada 3 bidang lahan yang dihibahkan warga ke Pemkot., yaitu lahan $70 \mathrm{~m}^{2}$ untuk pembangunan Instalasi pengelolaan air limbah dibagian bawah tanah, lalu diatasnya untuk ruang terbuka dan bank sampah. Lahan $130 \mathrm{~m} 2$ untuk Balai Pelatihan kelompok swadaya masyarakat (KSM) dan lahan seluas $18 \mathrm{~m} 2$ untuk pembangunan MCK 2 pintu. Ke 3 lahan tersebut tercatat pada Naskah Hibah No 22/SPJ/BPKAD/2016

Deskripsi SWOT : "Efektifitas Strategi Pemasaran Sosial Eksternal Rencana Pembangunan Program PLPBK di Kelurahan Sungai Lais Kecamatan Kalidoni Kotamadya Palembang."

\begin{tabular}{|c|c|c|c|c|}
\hline Kegiatan & $\begin{array}{c}\text { Kekuatan } \\
\text { (Strenghts) }\end{array}$ & $\begin{array}{c}\text { Kelemahan } \\
\text { (Weaknesses) }\end{array}$ & $\begin{array}{c}\text { Kesempatan } \\
\text { (Opportunities } \\
\text { ) }\end{array}$ & $\begin{array}{c}\text { Tantangan } \\
\text { (Threats) }\end{array}$ \\
\hline \multicolumn{5}{|l|}{$\begin{array}{l}\text { Efektifitas } \\
\text { strategi } \\
\text { pemasaran } \\
\text { sosial eksternal: }\end{array}$} \\
\hline Indikator & Pemerintah & Distribusi & Penataan ling- & Pemerintah Daerah \\
\hline $\begin{array}{l}\text { Proposal } \\
\text { penawaran } \\
\text { diterima dan ada } \\
\text { komitmen } \\
\text { Pemkot melalui } \\
\text { Bappeda untuk } \\
\text { mengintervensi } \\
\text { rencana } \\
\text { pembangu nan } \\
\text { fisik yg belum } \\
\text { terbiayai }\end{array}$ & $\begin{array}{l}\text { Daerah } \\
\text { membu- } \\
\text { tuhkan ide-ide } \\
\text { rencana } \\
\text { pemba- } \\
\text { ngunan dari } \\
\text { ma- syarakat } \\
\text { untuk } \\
\text { memperlancar } \\
\text { pembangunan } \\
\text { penataan }\end{array}$ & $\begin{array}{l}\text { Dana } \\
\text { pembangunan } \\
\text { dalam APBN } \\
\text { harus merata } \\
\text { untuk setiap } \\
\text { daerah di } \\
\text { Indone sia, } \\
\text { sehingga rea } \\
\text { lisasi rencana } \\
\text { pembangunan } \\
\text { bersifat }\end{array}$ & $\begin{array}{lr}\text { kungan } & \\
\text { permuki man } \\
\text { kumuh ada lah } \\
\text { program Nasi } \\
\text { onal dan } \\
\text { Pemerin tah } \\
\text { Daerah ber } \\
\text { tanggung } \\
\text { jawab untuk } \\
\text { merealisa } \\
\text { sikannya } \\
\end{array}$ & $\begin{array}{lr}\text { /kota Palembang } \\
\text { akan menginter } \\
\text { vensi } & \text { rencana } \\
\text { pembangunan } \\
\text { apabila } & \text { lahan } \\
\text { terdampak } & \text { pem } \\
\text { bangunan } & \text { sudah } \\
\text { dihibahkan } & \text { dan } \\
\text { terdaftar } & \text { di } \\
\text { BPKAD } & \text { Kota } \\
\text { Palembang. } & \end{array}$ \\
\hline
\end{tabular}




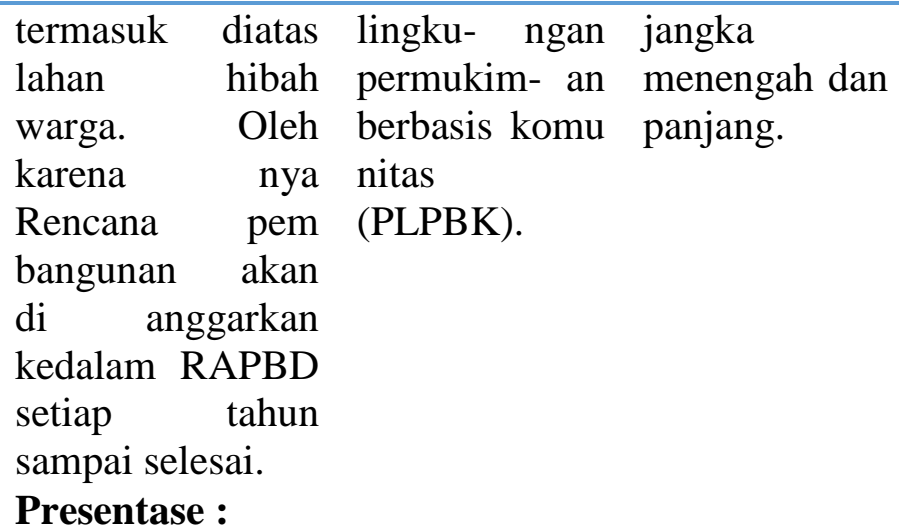

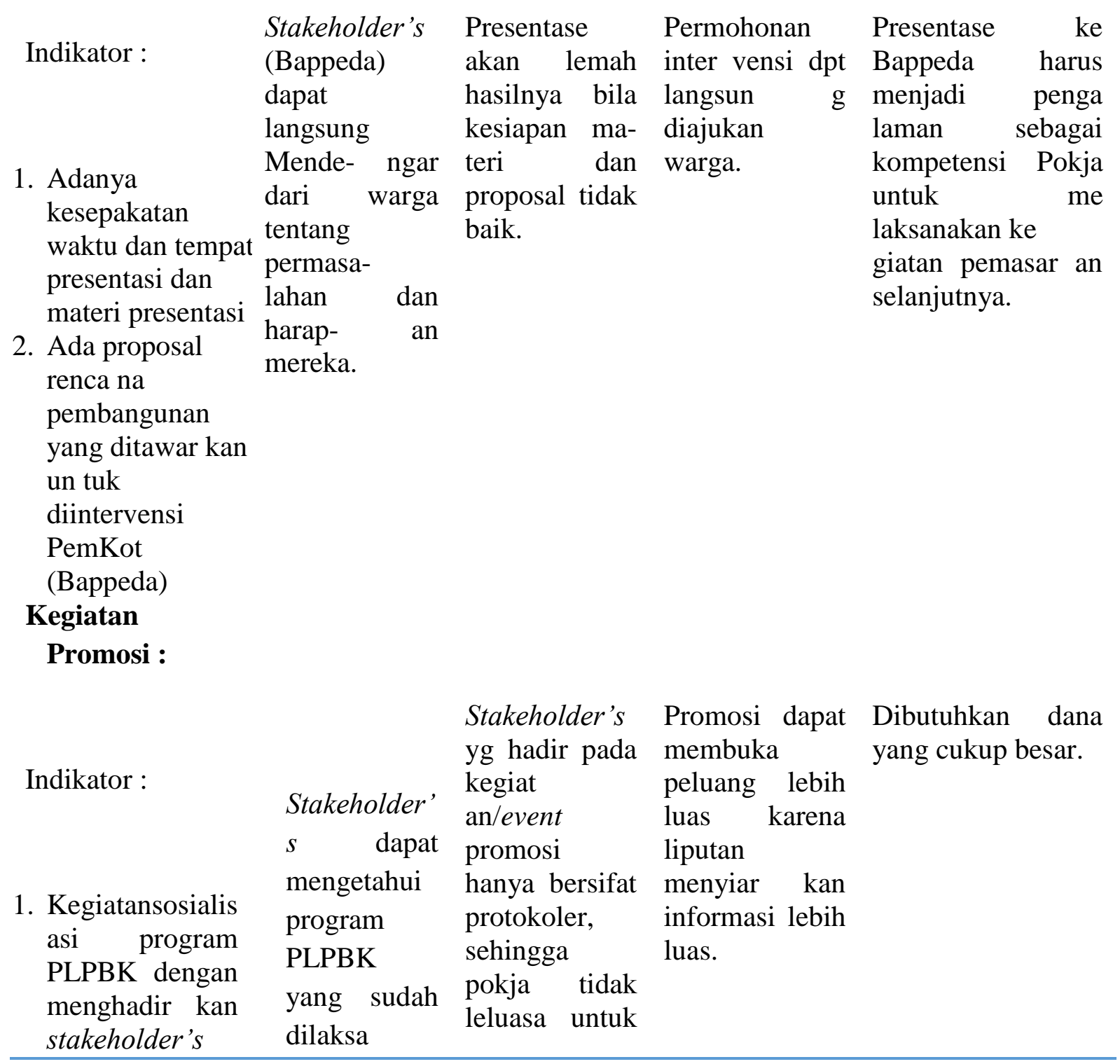




\begin{tabular}{lll}
\hline 2. Mengikuti & nakan dan & mempre \\
pameran & yg masih & $\begin{array}{l}\text { sentasekan } \\
\text { secara detail. }\end{array}$ \\
Palembang & membu- & \\
Expo & tuhkan inter- & \\
3. Pembagia & vensi & \\
n leafled, dan & sehingga & \\
bookled kepa da & dapat & \\
stakeholder's, & kedalam \\
penayangan 3D & RAPBD \\
video priori & Kota \\
kawasan prite & Palembang. \\
tas dan website &
\end{tabular}

Analisis SWOT : "Efektifitas Strategi Pemasaran Sosial Eksternal Rencana Pembangunan Program PLPBK di Kelurahan Sungai Lais Kecamatan Kalidoni Kotamadya Palembang."

Aggresive Strategy (S-O), Turn Around Strategy (S-T) dan Capaian Hasil

\begin{tabular}{|c|c|c|}
\hline EKSTERNAL & $\begin{array}{l}\text { Kesempatan } \\
\text { /Opportunities }\end{array}$ & Tantangan/Threats \\
\hline INTERNAL & $\begin{array}{l}\text { 1. Penataan lingkungan } \\
\text { permu- kiman kumuh } \\
\text { adalah prog ram } \\
\text { Nasional dan Pemerin- } \\
\text { tah Daerah bertanggung } \\
\text { jawab untuk } \\
\text { merealisasikan. } \\
\text { 2. Permohonan intervensi } \\
\text { dapat langsung diajukan } \\
\text { warga. } \\
\text { 3. Promosi dapat } \\
\text { membuka peluang lebih } \\
\text { luas karena liputan } \\
\text { menyiar kan informasi } \\
\text { lebih luas. }\end{array}$ & $\begin{array}{l}\text { 1. Pemerintah Daerah } \\
\text { /kota Palembang akan } \\
\text { mengin tervensi } \\
\text { rencana pemba } \\
\text { ngunan apabila lahan } \\
\text { terdampak } \\
\text { pembangunan sudah } \\
\text { dihibahkan dan } \\
\text { terdaftar di BPKAD } \\
\text { Kota Palembang. } \\
\text { 2. ke } \\
\text { Bappeda harus } \\
\text { menjadi pengalam an } \\
\text { sebagai kompetensi } \\
\text { Pokja untuk } \\
\text { melaksana kan } \\
\text { kegiatan pemasaran } \\
\text { selanjutnya. }\end{array}$ \\
\hline
\end{tabular}




\begin{tabular}{|c|c|c|}
\hline & & $\begin{array}{l}\text { 3. Dibutuhkan dana } \\
\text { yang besar. }\end{array}$ \\
\hline $\begin{array}{l}\text { Kekuatan (Strenghts) } \\
;\end{array}$ & $\begin{array}{c}\text { Aggresive Strategy (S- } \\
\text { O) }\end{array}$ & $\begin{array}{c}\text { Turn Around } \\
\text { Strategy } \\
(\mathrm{S}-\mathrm{T})\end{array}$ \\
\hline $\begin{array}{l}\text { 1. Pemerintah Daerah } \\
\text { mem butuhkan ide-ide } \\
\text { rencana pembangunan } \\
\text { dari warga untuk } \\
\text { memperlancar pena } \\
\text { taan lingkungan } \\
\text { permuki man berbasis } \\
\text { komu nitas }\end{array}$ & $\begin{array}{l}\text { Terus berupaya } \\
\text { mengajukan proposal ke } \\
\text { Bappeda dan } \\
\text { stakeholder's beserta } \\
\text { lahan yang sudah } \\
\text { dihibahkan dan siap } \\
\text { dibangun. }\end{array}$ & $\begin{array}{l}\text { LKM dan pokja harus } \\
\text { intent mengajukan } \\
\text { proposal pembangunan } \\
\text { kompetensi SDM ke } \\
\text { BUMN/BUMD dan } \\
\text { perusahaan swasta }\end{array}$ \\
\hline $\begin{array}{l}\text { 2. Stakeholder's } \\
\text { (Bappeda) dapat } \\
\text { langsung mende- } \\
\text { ngar dari warga } \\
\text { tentang masalah dan } \\
\text { harapan. }\end{array}$ & & \\
\hline \multicolumn{3}{|l|}{$\begin{array}{l}\text { 3. Stakeholder's dapat } \\
\text { menge tahui program } \\
\text { PLPBK yang sudah } \\
\text { dilaksanakan dan yg } \\
\text { masih membutuh kan } \\
\text { inter vensi sehingga } \\
\text { dapat dianggarkan } \\
\text { keda- lam RAPBD } \\
\text { Kota PLG. }\end{array}$} \\
\hline $\begin{array}{r}\text { Capaian } \\
\text { Surat Komitmen dari Pe } \\
\text { Bappeda bahwa Rencan } \\
\text { Lais akan diintervensi d }\end{array}$ & $\begin{array}{l}\text { Iasil Strategi Pemasaran } \\
\text { nerintah Kota Palembang yar } \\
\text { Pembangunan program PLP } \\
\text { igan APBD Kota Palembang }\end{array}$ & $\begin{array}{l}\text { ksternal : } \\
\text { g ditandatangani Kepala } \\
\text { 3K Kelurahan Sungai } \\
\text { setiap tahun. }\end{array}$ \\
\hline
\end{tabular}




\section{DAFTAR PUSTAKA}

Alma Buchori, 2010. "Pengantar Bisnis”. Alfabeta Febuari, Bandung.

Dokumen Rencana Tindak Penataan Lingkungan Permukiman Berbasis Komunitas (RTPLP) Kelurahan Sungai Lais, 2015

Dokumen Stategi Pemasaran PLPBK Kelurahan Sungai Lais, 2016

Kementerian Pekerjaan Umum Perumahan Rakyat,. "Juknis Pemasaran PLPBK." PNPM Mandiri Perkotaan, 2009.

Kementerian Pekerjaan Umum Dirjen Cipta Karya, 2014 "Petunjuk Umum PLPBK." PNPM Mandiri Perkotaan.

Kamus Besar Bahasa Indonesia, 2015.

Kotler Philip, 2014. Manajemen Pemasaran.” Rencana, Strategi,Implementasi. Salemba Empat, , Jakarta.

Lupiyoadi Rambat, 2014, "Manajemen Pemasaran Jasa" Berbasis Kompetensi. Salemba Empat, edisi 3, Jakarta.

Manullang, "Manajemen Pemasaran", Alfabata. Bandung.

Wikipedia. 27/12/2016Sukirno Sadono, 2014. Ekonomi Pembangunan. Edisi ke 2 cetakan ke 6, Kenacana Pranada Media Group, Jakarta.

Soegiono, 2003. "Metodologi Penelitian”, Bumi Aksara, Bandung 